\title{
Effects of Food on the Bioavailability of Amphetamine in Healthy Adults After Administration of SHP465 Mixed Amphetamine Salts Extended-Release Capsules
}

\author{
Yi Wang $^{1}{ }^{1} \cdot$ Ming Yu $^{1} \cdot$ Brian Yan $^{1} \cdot$ Patrick Martin $^{1} \cdot$ Brigitte Robertson $^{1}$
}

Published online: 26 March 2019

(c) The Author(s) 2019

\begin{abstract}
Background and objective SHP465 mixed amphetamine salts extended release is a once-daily, single-entity, mixed amphetamine salts capsule product for attention-deficit/hyperactivity disorder. The objective of this study was to evaluate amphetamine pharmacokinetics following SHP465 mixed amphetamine salts under three administration conditions.

Methods Healthy adults $(n=16)$ enrolled in an open-label, randomized, three-period crossover study with three singledose 50-mg SHP465 mixed amphetamine salts treatments (fasting $\geq 10 \mathrm{~h}$ before administration [reference]; high-fat meal consumption $30 \mathrm{~min}$ before administration; sprinkling capsule contents on applesauce) separated by $\geq 7$-day washouts. Blood samples for evaluating $d$ - and $l$-amphetamine pharmacokinetics were collected pre-dose and up to $60 \mathrm{~h}$ post-dose. Assessments included maximum plasma concentration, time to maximum plasma concentration, and area under the plasma concentration-time curve from 0 to infinity. Exponentiated least-squares mean ratios with $90 \%$ confidence intervals for test treatments relative to the reference treatment were calculated, with the absence of an effect indicated by the $90 \%$ confidence intervals falling within the $80-125 \%$ range.

Results Least-squares mean ( $90 \%$ confidence interval) ratios for maximum plasma concentration and area under the plasma concentration-time curve from 0 to infinity indicated neither consuming a high-fat meal $(d$-amphetamine: 85.33 [80.44, 90.50] and 91.11 [86.69, 95.75], respectively; $l$-amphetamine: 85.22 [80.18,90.59] and 88.74 [83.89, 93.87]) nor sprinkling the capsule contents on applesauce ( $d$-amphetamine: 95.76 [90.28, 101.57] and 95.77 [91.13, 100.65]; $l$-amphetamine: 96.90 $[91.16,103.00]$ and $94.78[89.60,100.26])$ altered amphetamine exposure. Consuming a high-fat meal prolonged median time to maximum plasma concentration for $d$ - and $l$-amphetamine by 5.0 and $4.5 \mathrm{~h}$, respectively, relative to reference treatment. Conclusions These findings demonstrate SHP465 mixed amphetamine salts capsules can be swallowed whole with or without food or the capsule contents can be sprinkled on applesauce.
\end{abstract}

\section{Introduction}

SHP465 mixed amphetamine salts (MAS) extended release (Mydayis ${ }^{\circledR}$; Shire, Lexington, MA, USA) is a once-daily, single-entity MAS capsule product for oral administration approved in USA for the treatment of attention-deficit/hyperactivity disorder (ADHD) in individuals aged 13 years and older [1]. SHP465 MAS contains equal amounts (by weight) of four salts: dextroamphetamine sulfate, amphetamine sulfate, dextroamphetamine saccharate, and amphetamine aspartate monohydrate; this results in

Yi Wang

yi.wang1@takeda.com

1 Shire (a member of the Takeda Group of Companies), 300 Shire Way, Lexington, MA 02421, USA

\section{Key Points}

Exposure to $d$ - and $l$-amphetamine was not altered by consuming a high-fat meal before taking SHP465 mixed amphetamine salts (MAS) or by sprinkling the contents of a SHP465 MAS capsule over applesauce, demonstrating that SHP465 MAS capsules can be swallowed whole with or without food or the contents of an SHP465 MAS capsule can be sprinkled on applesauce.

SHP465 MAS was generally well tolerated when administered as a single 50-mg dose in healthy adults, with a profile that was consistent with previously reported effects in adults with attention-deficit/hyperactivity disorder. 
a 3:1 mixture of $d$-amphetamine to $l$-amphetamine. Each SHP465 MAS capsule contains three types of drug-releasing beads (one immediate-release bead and two different types of delayed-release beads) in a 1:1:1 ratio [1].

The short-term efficacy and safety of SHP465 MAS in adults with ADHD have been examined in multiple phase III studies [2-4]. In a 7-week dose-optimization study, significantly greater reductions from baseline in the ADHD Rating Scale, Version IV total score were observed with SHP465 MAS (12.5-75 mg) than with placebo in adults with ADHD [3]. In 4- and 7-week forced-dose studies, SHP465 MAS produced significantly greater reductions in the ADHD Rating Scale With Adult Prompts (12.5 and $37.5 \mathrm{mg}$ ) [4] and the ADHD Rating Scale, Version IV $(25,50$, and $75 \mathrm{mg})$ [2] total scores than placebo in adults with ADHD. Across short-term efficacy studies [2-4], the safety and tolerability profile of SHP465 MAS was consistent with that of other long-acting psychostimulants.

Medication adherence is linked to several factors [5], including ease of drug administration [6, 7]. One method to increase the ease of taking medication is to eliminate the need to swallow a tablet or pill, which is an impediment to adherence in individuals who find it difficult to swallow tablets or capsules [6-8]. Individuals who experience difficulty swallowing tablets or capsules often alter the dosage form (e.g., crushing/chewing tablets, emptying capsule contents into a soft food) to ease administration, which may alter the agent's stability, efficacy, and safety [6, 7]. Further, food-drug interactions can affect the bioavailability of drugs, resulting in therapeutic failure from decreased bioavailability or poor tolerability owing to increased bioavailability $[9,10]$. High-fat foods in particular have the potential to influence drug bioavailability by altering drug absorption in the gastrointestinal tract $[9,10]$. Helping to address the issues associated with swallowing capsules or tablets, the administration directions for several medications approved for the treatment of ADHD (e.g., MAS extended release, methylphenidate extended release, dexmethylphenidate hydrochloride extended release, lisdexamfetamine) indicate that the contents of capsules may be sprinkled onto applesauce [11-14] or mixed with yogurt or orange juice [15] and specify that administration after a high-fat meal does not alter bioavailability $[11,12,14,15]$.

This study evaluated the pharmacokinetics of $d$ - and $l$-amphetamine when SHP465 MAS was administered after a high-fat meal or after the capsule contents were sprinkled on applesauce relative to consumption of an intact SHP465 MAS capsule in fasting healthy adults. The primary objective of the study was to assess the effect of a high-fat meal on the bioavailability of $50 \mathrm{mg}$ of SHP465 MAS relative to the fasted state. Secondary study objectives included assessment of the bioavailability of $50 \mathrm{mg}$ of SHP465 MAS after sprinkling the contents of an SHP465 MAS capsule over applesauce relative to the fasted state and the assessment of the safety and tolerability of $50 \mathrm{mg}$ of SHP465 MAS.

\section{Methods}

\subsection{Study Design and Treatment}

This phase I, open-label, randomized, single-dose, threeway crossover study in healthy adults (aged 18-55 years) was conducted from 27 December, 2004, to 26 January, 2005. The study protocol and informed consent form were approved by the Covance Clinical Research Unit Institutional Review Board (Madison, WI, USA). The study protocol was conducted in accordance with the principles of the 18th World Medical Assembly and amendments of the 29th, 35th, 41st, and 48th World Medical Assemblies and the International Conference on Harmonization Good Clinical Practices.

The study consisted of screening, baseline, and three single-dose treatment periods; each single-dose treatment period was separated by a $\geq 7$-day washout period (Fig. 1). At screening, which occurred within 28 days of check-in for the first treatment period, prospective participants received written information and an explanation of the study. All participants were required to give informed consent after having received this information; no study procedures were conducted before consent was provided.

Screening procedures included assessment of participant eligibility based on inclusion/exclusion criteria; collection of demographic, medical and medication history, and physical examination data; assessment of vital signs (after the participant was seated and at rest for $5 \mathrm{~min}$ ) and of a 12-lead electrocardiogram (after 5 min of rest); laboratory tests (hematology, serum biochemistry, urinalysis); a serum pregnancy test for women of child-bearing age; and a urine screen for alcohol and drugs of abuse.

After screening, eligible participants were randomized to a treatment sequence, using a randomization schedule employing two $3 \times 3$ Latin squares with each treatment condition (Fig. 1). Study participants were randomized into six dosing sequence groups $(\mathrm{ABC}, \mathrm{ACB}, \mathrm{BAC}, \mathrm{BCA}, \mathrm{CAB}$, and $\mathrm{CBA}$ ), where $\mathrm{A}$ was the fasted condition, $\mathrm{B}$ was the fed condition, and $\mathrm{C}$ was the sprinkled condition. Two or three participants were included in each sequence. For the fasted condition, $50 \mathrm{mg}$ of SHP465 MAS was administered as an intact capsule after a fast of $\geq 10 \mathrm{~h}$ (reference treatment). In the fed condition, $50 \mathrm{mg}$ of SHP465 MAS was given as an intact capsule $30 \mathrm{~min}$ after the start of a standard high-fat meal (approximately $800-1000$ calories, with approximately $50 \%$ of the calories from fat). In the sprinkled condition, $50 \mathrm{mg}$ of SHP465 MAS was administered after a fast of $\geq 10 \mathrm{~h}$, with the contents of the capsule ingested immediately after being 


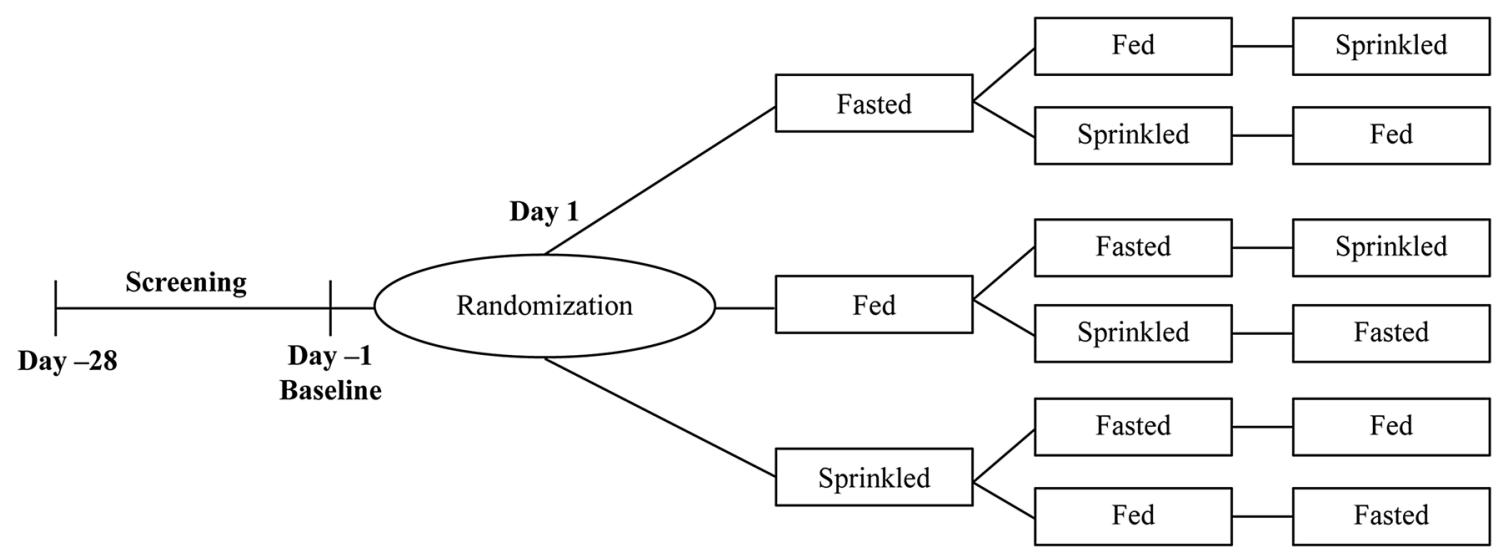

Fig. 1 Study design. Fasted condition: $50 \mathrm{mg}$ of SHP465 mixed amphetamine salts (MAS) as an intact capsule after a fast of $\geq 10 \mathrm{~h}$. Fed condition: $50 \mathrm{mg}$ of SHP465 MAS as an intact capsule $30 \mathrm{~min}$

sprinkled on a tablespoon of applesauce. Under each condition, SHP465 MAS was to be administered to the participant at approximately 8:00 a.m. with 8 ounces of water. Following treatment, all participants were required to fast for $4 \mathrm{~h}$, at which time a meal was provided. Participants were allowed to take naps during the post-dose period, with the exception of the first $4 \mathrm{~h}$ post-dose, and were not restricted from participating in organized activities. However, an increase above their usual activity level prior to and during the $60 \mathrm{~h}$ following dosing was prohibited. Participants were also prohibited from consuming foods or beverages containing alcohol, caffeine/xanthine, or ascorbic acid for $48 \mathrm{~h}$ before the baseline visit through $60 \mathrm{~h}$ post-dose.

On the morning before a scheduled treatment period, eligible participants were admitted to the clinic and the following procedures were conducted: confirmation of eligibility based on inclusion/exclusion criteria, a physical examination, an assessment of vital signs (after 5 min of rest) and of a 12-lead electrocardiogram (at 10:00 a.m., 12:00 p.m., and 4:00 p.m. after $5 \mathrm{~min}$ of rest), clinical laboratory tests, a serum pregnancy test for women of child-bearing age, a urine screen for alcohol and drugs of abuse, and assessment of concomitant medication and adverse events (AEs). Participants remained at the clinic until completion of the 60-h post-dose blood collection. All participants received a follow-up telephone call $30 \pm 5$ days after the last exposure to the study drug to assess AEs.

\subsection{Participants}

A total of 16 healthy adult (aged $18-55$ years) men and women with no clinically significant abnormal results and a body mass index between 20 and $29 \mathrm{~kg} / \mathrm{m}^{2}$ were eligible to participate in the study. Women were required to be postmenopausal, surgically sterile, or to have a negative serum following the start of a high-fat meal. Sprinkled condition: contents of a 50-mg SHP465 MAS capsule sprinkled on applesauce after a fast of $\geq 10 \mathrm{~h}$

pregnancy test before entering the study and were required to be using or agree to use acceptable contraception methods for the duration of the study and for 30 days after the last dose of study drug.

Individuals were excluded from the study if they had a current or recurrent disease that could affect the action, absorption, or disposition of SHP465 MAS or if they had any current disorder or medical history that may require treatment, reduce the likelihood of study completion, affect the validity of the study results, or present undue risk from the study drug or procedures or jeopardize the participant's safety. A history of uncontrolled hypertension, baseline systolic blood pressure (SBP) $>139 \mathrm{mmHg}$ or diastolic blood pressure $(\mathrm{DBP})>89 \mathrm{mmHg}$, or any known or suspected structural cardiac abnormality was also exclusionary. Additional criteria for exclusion were a history of alcohol or other substance abuse or a positive urine screen for drugs of abuse; the use of nicotine-containing products in any form; the use of any prescription medication within 14 days of baseline, any over-the-counter medication within 7 days of baseline, any known enzyme-altering agents within 30 days of baseline (or during the study) that could alter the pharmacokinetics of SHP465 MAS, or any investigational drug within 30 days of enrollment; a known or suspected intolerance or hypersensitivity to amphetamines or any related drugs; and a known or suspected allergy to apples, applesauce, or any food items in the high-fat meal.

\subsection{Endpoints}

\subsubsection{Pharmacokinetics}

Blood samples for the determination of plasma amphetamine concentrations were collected $30 \mathrm{~min}$ pre-dose (hour 0 ); at hourly intervals up to $10 \mathrm{~h}$ post-dose; and at 12,14 , 
$16,24,36,48$, and $60 \mathrm{~h}$ post-dose. Pharmacokinetic parameters assessed included maximum plasma concentration $\left(C_{\max }\right)$, time to $C_{\max }\left(t_{\max }\right)$, area under the plasma concentration-time curve from time 0 to the last measured time $\left(\mathrm{AUC}_{0 \text {-last }}\right)$ and from time 0 to infinity $\left(\mathrm{AUC}_{0 \text {-inf }}\right)$, terminal half-life $\left(t_{1 / 2}\right)$, and the terminal phase rate constant $\left(\lambda_{z}\right)$. The linear trapezoidal rule was used to calculate area under the curve. The pharmacokinetic parameters were calculated with non-compartmental techniques using WinNonlin ${ }^{\circledR}$ Professional, Version 4.1 (Pharsight Corporation, Mountainview, CA, USA).

\subsubsection{Bioanalytical Methods}

Validated liquid chromatography with tandem mass spectrometry was used to evaluate $d$ - and $l$-amphetamine levels. Plasma concentrations were calculated using an eight-point standard curve $(0.5-75 \mathrm{ng} / \mathrm{mL})$. Assay precision ranged from 0.8 to $6.2 \%$ for $d$-amphetamine and from $1.1-4.6 \%$ for $l$-amphetamine. Assay accuracy ranged from 90.8 to $108.1 \%$ for $d$-amphetamine and from 91.3 to $107.3 \%$ for $l$-amphetamine. Plasma samples $<0.5$ or $>75 \mathrm{ng} / \mathrm{mL}$ were considered below the lower limit or above the upper limit of quantification, respectively. Samples were assayed simultaneously with calibration standards and quality-control samples that were prepared in a $0.5-\mathrm{mL}$ aliquot of ethylenediaminetetraacetic acid human plasma.

Samples were extracted along with a deuterated, racemic, amphetamine internal standard by liquid-liquid extraction into hexane, followed by back extraction into acid; sodium ethylenediaminetetraacetic acid was used as an anticoagulant. Following realkalinization, the analytes were derivatized with benzoyl chloride, and the benzoyl derivatives of amphetamine were extracted into hexane. Extracts were dried, reconstituted in the mobile phase, and injected onto a chiral, high-performance liquid chromatography column (Chiralcel ${ }^{\circledR} \mathrm{OB}-\mathrm{H}$ $5 \mu \mathrm{m}, 4.6 \times 150 \mathrm{~mm}$ with a guard of Chiralcel ${ }^{\circledR}$ OB $10 \mu \mathrm{m}$, $4.6 \times 50 \mathrm{~mm})$. After separation of the analytes, ammonium formate was introduced as a post-column addition to improve analyte ionization. All compounds were detected by operating the system in multiple reaction monitoring mode. The transitions monitored were $\mathrm{m} / \mathrm{z} 240 \rightarrow 91$ for amphetamine and $\mathrm{m} / \mathrm{z}$ $246 \rightarrow 93$ for the deuterated amphetamine. Micromass MassLynx $^{\mathrm{TM}}$, Version 4.0 (Waters Corporation, Milford, MA, USA) software was used for data acquisition.

\subsubsection{Safety and Tolerability}

Safety and tolerability measures included assessments of treatment-emergent AEs (TEAEs) and vital signs. Vital signs (including pulse, SBP, and DBP) were collected after the participant had been seated for $5 \mathrm{~min}$ at $30 \mathrm{~min}$ pre-dose (hour 0 ) and 2, 4, 8, 12, 24, and $60 \mathrm{~h}$ post-dose. Twelve-lead electrocardiograms were obtained following $5 \mathrm{~min}$ of rest at hour 0 and at 2, 4, 8, 12, 24, and $60 \mathrm{~h}$ post-dose. The occurrence of AEs and use of concomitant medications were recorded throughout each treatment period.

\subsection{Data and Statistical Analyses}

A formal sample size calculation was not performed for this study owing to limited data being available for estimation at the time the study was conducted. Pharmacokinetic analyses were conducted in the pharmacokinetic population, defined as all participants who received one or more doses of SHP465 MAS and who had evaluable concentration-time profiles for $d$ - or $l$-amphetamine. Pharmacokinetic parameters are reported descriptively and were analyzed using analysis of variance with sequence, period, and treatment as fixed effects and participant nested within a sequence as a random effect; natural $\log$ transformations were used to assess $C_{\text {max }}, \mathrm{AUC}_{0 \text {-inf }}$,

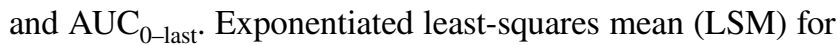
each treatment were obtained for $C_{\text {max }}, \mathrm{AUC}_{0-\text { inf }}$, and $\mathrm{AUC}_{0-\text { last }}$, and the ratios of the exponentiated LSM with $90 \%$ confidence intervals for each test condition (fed and sprinkled) relative to the reference condition (fasted) were calculated. If the $90 \%$ confidence intervals for the LSM ratio fell within the range of $80-125 \%$, it was considered to indicate the absence of an effect of consuming a high-fat meal or of sprinkling the capsule contents onto applesauce on the bioavailability of SHP465 MAS relative to the fasted state. Statistical analyses were conducted using SAS (SAS Institute Inc., Cary, NC, USA).

Safety and tolerability endpoints were assessed in the safety population, defined as all participants who received one or more SHP465 MAS doses during the study. Safety and tolerability data are reported using descriptive statistics.

\section{Results}

\subsection{Participant Disposition and Demographics}

All 16 enrolled participants were included in the safety population and pharmacokinetic population. Fourteen participants completed the study, with two participants discontinuing because of an AE (one case of vomiting that occurred 8 days after receiving the second treatment [50 mg of SHP465 sprinkled over applesauce] that was considered to be of mild intensity and not related to the study drug; one case of anxiety that occurred in the afternoon following the second treatment [50 mg of SHP465 sprinkled over applesauce] that was considered to be of mild intensity and probably related to the study drug). Table 1 summarizes participant demographics and clinical characteristics. 


\subsection{Pharmacokinetics}

Plasma concentration-time curves for $d$ - and $l$-amphetamine under each treatment condition are shown in Fig. 2. Both $d$ and $l$-amphetamine were quantifiable at 1 -h post-dose and peaked between 7 and $8 \mathrm{~h}$ post-dose under the fasted and sprinkled treatment conditions. Under the fed treatment condition, amphetamine concentrations peaked at approximately $12 \mathrm{~h}$ and were lower than under the fasted and sprinkled treatment conditions.

Pharmacokinetic endpoints across treatment conditions are summarized descriptively for $d$ - and $l$-amphetamine in Table 2. Consistent with observations based on the plasma concentration-time curves, relative to the fasted (reference) treatment condition, consuming a high-fat meal prolonged median $t_{\max }$ for $d$-amphetamine by $5 \mathrm{~h}$ (from 7 to $12 \mathrm{~h}$ ) and for $l$-amphetamine by $4.5 \mathrm{~h}$ (from 7.5 to $12 \mathrm{~h}$ ). Median $C_{\max }$ for $d$-amphetamine $(60.28 \mathrm{ng} / \mathrm{mL})$ and $l$-amphetamine $(17.32 \mathrm{ng} / \mathrm{mL})$ also tended to be lower after a high-fat meal compared with the fasted condition (70.32 and $20.45 \mathrm{ng} / \mathrm{mL}$, respectively), but $C_{\max }$ concentrations were largely overlapping. Based on exponentiated LSM (90\% confidence interval) ratios for $C_{\max }, \mathrm{AUC}_{0 \text {-inf }}$, and $\mathrm{AUC}_{0-\text { last }}$, neither a highfat meal nor sprinkling the contents of a 50-mg SHP465 MAS capsule on applesauce altered $d$ - or $l$-amphetamine exposure relative to the fasted treatment condition (Table 3 ).

\subsection{Safety and Tolerability}

No deaths or serious AEs occurred during the study. Most study participants $(14 / 16 ; 87.5 \%)$ reported one or more TEAE. All TEAEs were of mild or moderate intensity. No serious TEAEs were reported. Of the two participants who withdrew from the study because of AEs, only one instance (a case of anxiety in a participant under the sprinkled treatment condition) was considered to be a TEAE.

Table 1 Participant demographic and baseline clinical characteristics, safety population

\begin{tabular}{ll}
\hline Characteristics & Total $(n=16)$ \\
\hline Mean \pm SD age, years & $32.8 \pm 12.51$ \\
Sex, $n(\%)$ & \\
Male & $9(56.3)$ \\
Female & $7(43.8)$ \\
Race, $n(\%)$ & \\
White & $15(93.8)$ \\
Black/African American & $1(6.3)$ \\
Mean \pm SD weight, kg & $73.7 \pm 10.16$ \\
Mean \pm SD height, $\mathrm{cm}$ & $173.8 \pm 11.62$ \\
Mean \pm SD BMI, $\mathrm{kg} / \mathrm{m}^{2}$ & $24.46 \pm 2.049$ \\
\hline
\end{tabular}

$B M I$ body mass index, $S D$ standard deviation

\section{a $d$-Amphetamine}

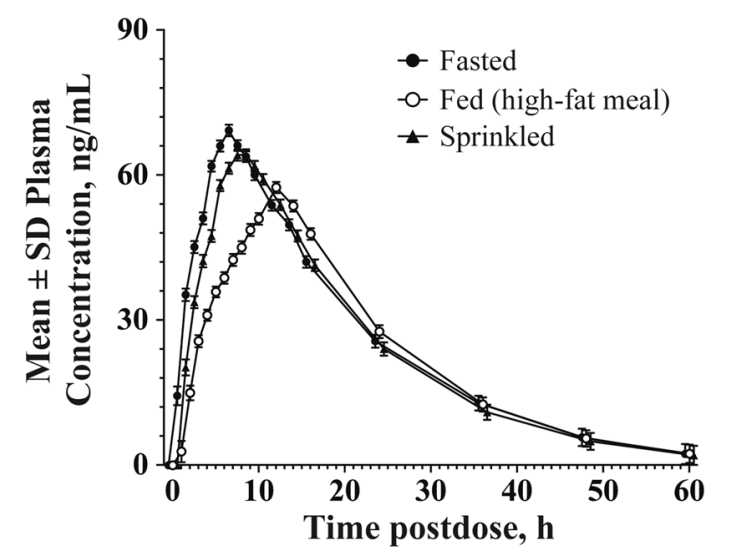

b -Amphetamine

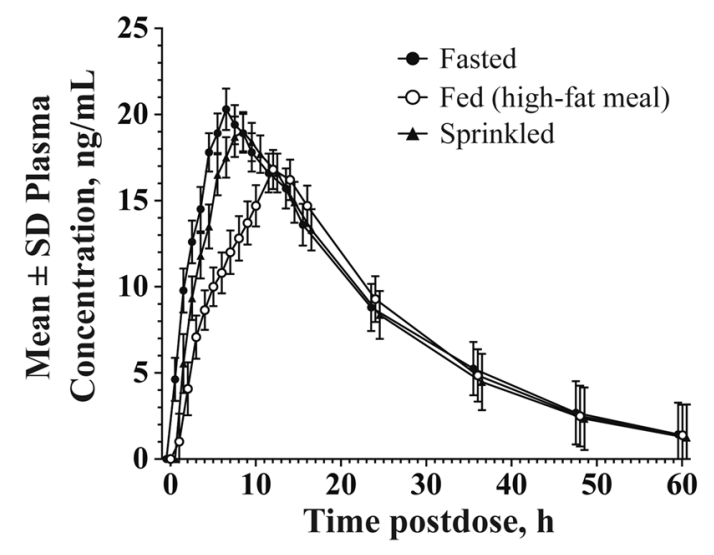

Fig. 2 a $d$-Amphetamine and $\mathbf{b} l$-amphetamine plasma concentrationtime curves with $50 \mathrm{mg}$ of SHP465 mixed amphetamine salts (MAS), pharmacokinetic population ${ }^{\mathrm{a}}$. Fasted condition: $50 \mathrm{mg}$ of SHP465 MAS as an intact capsule after a fast of $\geq 10 \mathrm{~h}$. Fed condition: $50 \mathrm{mg}$ of SHP465 MAS as an intact capsule $30 \mathrm{~min}$ following the start of a high-fat meal. Sprinkled condition: contents of a 50-mg SHP465 MAS capsule sprinkled on applesauce after a fast of $\geq 10 \mathrm{~h}$. ${ }^{\mathrm{a}}$ Data are the geometric mean \pm the geometric standard deviation (SD)

Treatment-emergent adverse events reported by two or more participants across any treatment condition are summarized in Table 4 . The most frequently reported TEAEs were anorexia, headache, increased energy, and dry mouth.

The magnitude of mean pulse changes was comparable across treatment conditions, with maximum mean \pm standard deviation increases being observed at $12 \mathrm{~h}$ post-dose across all conditions (fasted: $25.6 \pm 11.06 \mathrm{bpm}$; fed: $23.9 \pm 13.24$ bpm; sprinkled: $28.3 \pm 18.70 \mathrm{bpm}$ ). Increases in SBP tended to be lower under the fed condition compared with the other treatment conditions; the maximum mean \pm standard deviation increase in SBP was observed at $2 \mathrm{~h}$ post-dose in the fasted condition $(23.0 \pm 14.28 \mathrm{mmHg})$ and at $8 \mathrm{~h}$ post-dose in the fed $(15.9 \pm 11.12 \mathrm{mmHg})$ and 
Table 2 Pharmacokinetic parameters by treatment, pharmacokinetic population $^{\mathrm{a}}$

\begin{tabular}{|c|c|c|c|c|c|c|}
\hline & $C_{\max }, \mathrm{ng} / \mathrm{mL}$ & $\begin{array}{l}\mathrm{AUC} \mathrm{C}_{0 \text { inf }} \\
\mathrm{h} \cdot \mathrm{ng} / \mathrm{mL}\end{array}$ & $\begin{array}{l}\mathrm{AUC}_{0-\text { last }} \\
\mathrm{h} \cdot \mathrm{ng} / \mathrm{mL}\end{array}$ & $t_{\max }, \mathrm{h}$ & $t_{1 / 2}, \mathrm{~h}$ & $\lambda_{z}$ \\
\hline \multicolumn{7}{|c|}{$d$-Amphetamine } \\
\hline \multicolumn{7}{|c|}{$\operatorname{Fed}^{\mathrm{b}}(n=16)$} \\
\hline Mean & 59.6 & 1400 & 1360 & $12(8.0-14.0)$ & 10.4 & 0.0669 \\
\hline $\mathrm{CV} \%$ & 11.7 & 21.9 & 19.8 & 16.33 & 18.2 & 18.2 \\
\hline \multicolumn{7}{|c|}{ Sprinkled $^{\mathrm{c}}(n=16)$} \\
\hline Mean & 66.9 & 1470 & 1430 & $7.5(5.0-9.0)$ & 10.4 & 0.0668 \\
\hline $\mathrm{CV} \%$ & 11.6 & 18.8 & 16.8 & 18.47 & 19.3 & 19.3 \\
\hline \multicolumn{7}{|c|}{ Fasted $^{\mathrm{d}}(n=14)$} \\
\hline Mean & 71.2 & 1560 & 1510 & $7(6.0-10.0)$ & 10.7 & 0.0651 \\
\hline $\mathrm{CV} \%$ & 18.0 & 20.7 & 18.0 & 15.63 & 22.2 & 22.2 \\
\hline \multicolumn{7}{|c|}{ l-Amphetamine } \\
\hline \multicolumn{7}{|c|}{$\mathrm{Fed}^{\mathrm{b}}(n=16)$} \\
\hline Mean & 17.4 & 466 & 437 & $12(8.0-14.0)$ & 12.5 & 0.0555 \\
\hline $\mathrm{CV} \%$ & 12.3 & 26.4 & 22.7 & 15.63 & 24.3 & 24.3 \\
\hline \multicolumn{7}{|c|}{ Sprinkled $^{\mathrm{c}}(n=16)$} \\
\hline Mean & 19.8 & 497 & 470 & $8(5.0-12.0)$ & 12.7 & 0.0546 \\
\hline $\mathrm{CV} \%$ & 12.6 & 24.3 & 21.0 & 23.14 & 22.8 & 22.8 \\
\hline \multicolumn{7}{|c|}{ Fasted $^{\mathrm{d}}(n=14)$} \\
\hline Mean & 20.8 & 529 & 497 & $7.5(6.0-12.0)$ & 13.1 & 0.0527 \\
\hline $\mathrm{CV} \%$ & 16.9 & 25.2 & 20.7 & 25.95 & 26.4 & 26.4 \\
\hline
\end{tabular}

$A U C_{0-i n f}$ area under the plasma concentration-time curve from time 0 to infinity, $A U C_{0-\text { last }}$ area under the plasma concentration-time curve from time 0 to the last measured time, $C_{\max }$ maximum plasma concentration, $C V \%$ percent coefficient of variation, $\lambda_{z}$ terminal phase rate constant, $M A S$ mixed amphetamine salts, $t_{1 / 2}$ terminal half-life, $t_{\max }$ time to $C_{\max }$

${ }^{a}$ Data are geometric mean and geometric $\mathrm{CV} \%$, except for $t_{\max }$, which is the median (minimum-maximum) and $\mathrm{CV} \%$

${ }^{\mathrm{b}} 50 \mathrm{mg}$ of SHP465 MAS as an intact capsule $30 \mathrm{~min}$ following the start of a high-fat meal

c50 mg of SHP465 MAS after a fast of $\geq 10 \mathrm{~h}$ when the contents of the capsule were sprinkled on applesauce

d $50 \mathrm{mg}$ of SHP465 MAS as an intact capsule after a fast of $\geq 10 \mathrm{~h}$ (reference condition)

Table 3 Exponentiated least-squares means (LSM) and ratios by treatment, pharmacokinetic population

\begin{tabular}{|c|c|c|c|c|c|c|}
\hline & \multicolumn{2}{|l|}{$C_{\max }, \mathrm{ng} / \mathrm{mL}$} & \multicolumn{2}{|c|}{$\mathrm{AUC}_{0-\text { inf }}, \mathrm{h} \cdot \mathrm{ng} / \mathrm{mL}$} & \multicolumn{2}{|c|}{$\mathrm{AUC}_{0-\text { last }}, \mathrm{h} \cdot \mathrm{ng} / \mathrm{mL}$} \\
\hline & $\begin{array}{l}\text { Exponentiated } \\
\text { LSM }\end{array}$ & $\begin{array}{l}\text { Ratio ( } 90 \% \text { CI) of } \\
\text { exponentiated LSM }\end{array}$ & $\begin{array}{l}\text { Exponentiated } \\
\text { LSM }\end{array}$ & $\begin{array}{l}\text { Ratio }(90 \% \text { CI) of } \\
\text { exponentiated LSM }\end{array}$ & $\begin{array}{l}\text { Exponentiated } \\
\text { LSM }\end{array}$ & $\begin{array}{l}\text { Ratio }(90 \% \text { CI) of } \\
\text { exponentiated LSM }\end{array}$ \\
\hline \multicolumn{7}{|l|}{$d$-Amphetamine } \\
\hline $\operatorname{Fed}^{\mathrm{a}}(n=16)$ & 59.4 & $85.33(80.44-90.50)$ & 1392.5 & $91.11(86.69-95.75)$ & 1350.3 & 90.98 (86.71-95.46) \\
\hline Sprinkled $^{\mathrm{b}}(n=16)$ & 66.7 & $95.76(90.28-101.57)$ & 1463.7 & $95.77(91.13-100.65)$ & 1424.5 & $95.97(91.47-100.70)$ \\
\hline Fasted $^{\mathrm{c}}(n=14)$ & 69.6 & NA & 1528.3 & NA & 1484.2 & NA \\
\hline \multicolumn{7}{|l|}{ l-Amphetamine } \\
\hline $\operatorname{Fed}^{\mathrm{a}}(n=16)$ & 17.4 & $85.22(80.18-90.59)$ & 463.4 & 88.74 (83.89-93.87) & 436.1 & $88.61(83.85-93.65)$ \\
\hline Sprinkled $^{\mathrm{b}}(n=16)$ & 19.8 & $96.90(91.16-103.00)$ & 495.0 & $94.78(89.60-100.26)$ & 468.1 & $95.12(90.00-100.52)$ \\
\hline Fasted $^{\mathrm{c}}(n=14)$ & 20.4 & NA & 522.3 & NA & 492.2 & NA \\
\hline
\end{tabular}

$A U C_{0-i n f}$ area under the plasma concentration-time curve from time 0 to infinity, $A U C_{0-l a s t}$ area under the plasma concentration-time curve from time 0 to the last measured time, $C I$ confidence interval, $C_{\max }$ maximum plasma concentration, $M A S$ mixed amphetamine salts, $N A$ not applicable a $50 \mathrm{mg}$ of SHP465 MAS as an intact capsule 30 min following the start of a high-fat meal

${ }^{b} 50 \mathrm{mg}$ of SHP465 MAS after a fast of $\geq 10 \mathrm{~h}$ when the contents of the capsule were sprinkled on applesauce

c $50 \mathrm{mg}$ of SHP465 MAS as an intact capsule after a fast of $\geq 10 \mathrm{~h}$ (reference condition) 
sprinkled $(23.4 \pm 14.21 \mathrm{mmHg})$ conditions. Increases in DBP also tended to be lower under the fed condition compared with the other treatment conditions; the mean \pm maximum increase in DBP was observed at $2 \mathrm{~h}$ post-dose in the fasted condition $(11.7 \pm 6.70 \mathrm{mmHg})$, at $4 \mathrm{~h}$ post-dose in the sprinkled condition $(6.4 \pm 8.95 \mathrm{mmHg})$, and at 8 and 12 $h$ post-dose $(6.8 \pm 7.01$ and $6.8 \pm 7.69$, respectively) in the fed condition.

\section{Discussion}

The purpose of this study was to evaluate the pharmacokinetics of $d$ - and $l$-amphetamine when $50 \mathrm{mg}$ of SHP465 MAS was administered following a high-fat meal or after the contents of a 50-mg SHP465 MAS capsule was sprinkled on applesauce compared with administration following a 10 -h fast. The results indicate that exposure to $d$ - and $l$-amphetamine is not altered by consumption of a high-fat meal before SHP465 MAS administration or by sprinkling the contents of an SHP465 MAS capsule on applesauce before ingestion. This demonstrates that SHP465 MAS can be swallowed whole with or without food or the contents of an SHP465 MAS capsule can be sprinkled on applesauce. This is consistent with reports for other ADHD medications [16-19], one of which is extended-release MAS, [16] which have also indicated that amphetamine or methylphenidate exposure is not significantly altered by consumption of a high-fat meal or by sprinkling/mixing the contents of capsules with a soft food [16-19].

Consumption of a high-fat meal delayed median $t_{\max }$ for $d$ - and $l$-amphetamine relative to the fasted condition by $5 \mathrm{~h}$ and $4.5 \mathrm{~h}$, respectively. This finding is consistent with a previous study of MAS extended release that reported delays in $t_{\max }$ of 2 and $3 \mathrm{~h}$ for $d$ - and $l$-amphetamine, respectively, after a high-fat meal [16]. It is also consistent with a published report of extended-release orally disintegrating amphetamine, which reported delayed $t_{\max }$ of 2 and $2.25 \mathrm{~h}$ for $d$ - and $l$-amphetamine, respectively, after a highfat high-calorie meal [20]. The median $t_{\max }$ and ranges for $d$ - and $l$-amphetamine were the same under the fed condition and were similar under the fasted and sprinkled conditions. The small differences observed across conditions is not expected to have any clinical impact based on the pharmacological potency of $d$ - and $l$-amphetamine. The observed $t_{\max }$ values for the fasted and sprinkled conditions are also generally consistent with those reported by Ermer et al. [21]. There were no observed treatment differences for elimination of $d$ - or $l$-amphetamine, as measured by $t_{1 / 2}$ or $\lambda_{z}$, indicating that administration of SHP465 MAS with a meal did not alter the elimination characteristics of either enantiomer.

The safety and tolerability profile of $50 \mathrm{mg}$ of SHP 465 MAS in healthy adults in this study was generally consistent with previous observations from short-term phase III studies of SHP465 in adults with ADHD [2-4] and for other amphetamine-based psychostimulants in healthy
Table 4 Treatment-emergent adverse events (TEAEs) by treatment condition, safety population

\begin{tabular}{llll}
\hline TEAEs & Fasted $^{\mathrm{a}}(n=14)$ & Fed $^{\mathrm{b}}(n=16)$ & Sprinkled $^{\mathrm{c}}(n=16)$ \\
\hline Participants with $\geq 1$ TEAE, $n(\%)$ & $8(57.1)$ & $8(50.0)$ & $10(62.5)$ \\
TEAEs reported by $\geq 2$ participants across treatment conditions, & $n(\%)$ & \\
Anorexia & $1(7.1)$ & $5(31.3)$ & $3(18.8)$ \\
Headache & $2(14.3)$ & $3(18.8)$ & $3(18.8)$ \\
Energy increased & $2(14.3)$ & $1(6.3)$ & $3(18.8)$ \\
Dry mouth & 0 & $2(12.5)$ & $2(12.5)$ \\
Anxiety & $1(7.1)$ & 0 & $2(12.5)$ \\
Nausea & $1(7.1)$ & $1(6.3)$ & $1(6.3)$ \\
Circumoral paresthesia & $1(7.1)$ & $1(6.3)$ & $1(6.3)$ \\
Tremor & $1(7.1)$ & $1(6.3)$ & $1(6.3)$ \\
Insomnia & $1(7.1)$ & $1(6.3)$ & $1(6.3)$ \\
Blood pressure increased & $1(7.1)$ & $1(6.3)$ & 0 \\
Palpitations & $1(7.1)$ & $1(6.3)$ & 0 \\
Feeling jittery & 0 & 0 & $2(12.5)$ \\
Dizziness & $2(14.3)$ & 0 & 0 \\
\hline
\end{tabular}

MAS mixed amphetamine salts

a $50 \mathrm{mg}$ of SHP465 MAS as an intact capsule after a fast of $\geq 10 \mathrm{~h}$ (reference condition)

b50 mg of SHP465 MAS as an intact capsule 30 min following the start of a high-fat meal

${ }^{c} 50 \mathrm{mg}$ of SHP465 MAS after a fast of $\geq 10 \mathrm{~h}$ when the contents of the capsule were sprinkled on applesauce 
adults $[16,17,19,20]$ and adults with ADHD [22, 23]. The most frequently reported TEAEs in this study were anorexia, headache, increased energy, and dry mouth. The most frequently reported TEAEs in healthy adults included decreased appetite, dry mouth, palpitations, and headache with lisdexamfetamine [17, 19] and insomnia, headache, nausea, and dizziness with MAS extended release [16]. Across phase III studies of SHP465 MAS in adults with ADHD, the most frequently reported TEAEs included decreased appetite, dry mouth, insomnia, and headache [2-4]. Mean pulse and blood pressure increased following SHP465 MAS treatment across all treatment conditions, although smaller magnitude blood pressure increases were observed during the fed condition than during the fasted and sprinkled conditions. As with the TEAE profile of SHP465 MAS, the observed increases in pulse and blood pressure are consistent with findings from phase III studies of SHP465 MAS in adults with ADHD [2-4] and from studies of other psychostimulants in healthy adults [16, 17, 19]. Although the effects of SHP465 MAS on vital signs were expected and did not lead to clinically relevant events, it is recommended that vital signs be monitored regularly during treatment with psychostimulants [24, 25]. The time course of changes in blood pressure and heart rate observed in the current study, with increases in blood pressure peaking earlier than increases in heart rate, has been observed in studies of SHP465 MAS [21] and other psychostimulants $[17,26]$. At this time, the mechanisms responsible for this pattern of changes are not known. However, the differential time course of changes was small, transitory, and not expected to be clinically important

These data should be considered in light of several limitations. First, the safety and tolerability findings from this phase I study should be interpreted with caution because of the small sample size and the short duration of exposure. Furthermore, because of the nature of this singledose study, it cannot be determined if differences in bioavailability would be observed between administration conditions with other SHP465 MAS doses.

\section{Conclusions}

Exposure to $d$ - and $l$-amphetamine following $50 \mathrm{mg}$ of SHP465 MAS was not altered by consumption of a highfat meal or by sprinkling the contents of a capsule over applesauce, as measured by $C_{\max }, \mathrm{AUC}_{0-\text { inf }}$, and AUC 0-last. This demonstrates that SHP465 MAS capsules can be swallowed whole with or without food and that the contents of a capsule can be added to a spoonful of applesauce and immediately consumed. The ability to take SHP465 MAS with or without food or by sprinkling the contents of a capsule on applesauce allows for flexibility in administration and eases administration difficulties for individuals who are unable to swallow a tablet or capsule. SHP465 MAS was generally well tolerated when administered as a single 50-mg dose in healthy adults.

Acknowledgements Under the direction of the authors, writing assistance was provided by Madhura Mehta, $\mathrm{PhD}$, Wendy van der Spuy, $\mathrm{PhD}$, and Craig Slawecki, PhD, employees of Complete Healthcare Communications, LLC (CHC; North Wales, PA, USA) a CHC Group company. Editorial assistance in the form of proofreading, copyediting, and fact checking was also provided by CHC. Shailesh Desai, PhD, from Shire, a member of the Takeda group of companies, reviewed and edited the content of this article for scientific accuracy.

\section{Compliance with Ethical Standards}

Funding This clinical research was funded by the sponsor, Shire Development LLC, Lexington, MA, USA, a member of the Takeda group of companies. Shire Development LLC, Lexington, MA, USA, a member of the Takeda group of companies, provided funding to CHC for support in writing and editing this article.

Conflict of interest Yi Wang, Ming Yu, Brian Yan, Patrick Martin, and Brigitte Robertson are employees of Shire, a member of the Takeda group of companies, and hold Takeda stock and/or stock options.

Ethics approval The study protocol and informed consent form were approved by the Covance Clinical Research Unit Institutional Review Board (Madison, WI, USA). The study protocol was conducted in accordance with the principles of the 18th World Medical Assembly and amendments of the 29th, 35th, 41st, and 48th World Medical Assemblies.

Consent to participate All participants were required to give informed consent after having received written information and an explanation of the study; no study procedures were conducted before consent was provided.

Data availability The datasets generated during and/or analyzed during the current study are not publicly available.

Open Access This article is distributed under the terms of the Creative Commons Attribution-NonCommercial 4.0 International License (http://creativecommons.org/licenses/by-nc/4.0/), which permits any noncommercial use, distribution, and reproduction in any medium, provided you give appropriate credit to the original author(s) and the source, provide a link to the Creative Commons license, and indicate if changes were made.

\section{References}

1. Mydayis ${ }^{\circledR}$ extended-release capsules (mixed salts of a singleentity amphetamine product): US prescribing information. Lexington (MA): Shire US Inc., 2017.

2. Frick G, Yan B, Adler LA. Triple-bead mixed amphetamine salts (SHP465) in adults with ADHD: results of a phase 3, doubleblind, randomized, forced-dose trial. J Atten Disord. https://doi org/10.1177/1087054717696771 (epub ahead of print). 
3. Spencer TJ, Adler LA, Weisler RH, Youcha SH. Triple-bead mixed amphetamine salts (SPD465), a novel, enhanced extendedrelease amphetamine formulation for the treatment of adults with ADHD: a randomized, double-blind, multicenter, placebo-controlled study. J Clin Psychiatry. 2008;69(9):1437-48.

4. Weisler RH, Greenbaum M, Arnold V, Yu M, Yan B, Jaffee M, et al. Efficacy and safety of SHP465 mixed amphetamine salts in the treatment of attention-deficit/hyperactivity disorder in adults: results of a randomized, double-blind, placebo-controlled, forceddose clinical study. CNS Drugs. 2017;31(8):685-97.

5. Ingersoll KS, Cohen J. The impact of medication regimen factors on adherence to chronic treatment: a review of literature. J Behav Med. 2008;31(3):213-24.

6. Mc Gillicuddy A, Crean AM, Sahm LJ. Older adults with difficulty swallowing oral medicines: a systematic review of the literature. Eur J Clin Pharmacol. 2016;72(2):141-51.

7. Fields J, Go JT, Schulze KS. Pill properties that cause dysphagia and treatment failure. Curr Ther Res Clin Exp. 2015;77:79-82.

8. Charach A, Skyba A, Cook L, Antle BJ. Using stimulant medication for children with ADHD: what do parents say? A brief report. J Can Acad Child Adolesc Psychiatry. 2006;15(2):75-83.

9. Schmidt LE, Dalhoff K. Food-drug interactions. Drugs. 2002;62(10):1481-502.

10. Won CS, Oberlies NH, Paine MF. Mechanisms underlying fooddrug interactions: inhibition of intestinal metabolism and transport. Pharmacol Ther. 2012;136(2):186-201.

11. Adderall $\mathrm{XR}^{\circledR}$ (mixed salts of a single-entity amphetamine product): US prescribing information. Lexington (MA): Shire US Inc., 2017.

12. Focalin $\mathrm{XR}^{\circledR}$ (dexmethylphenidate hydrochloride extendedrelease capsule): US prescribing information. East Hanover (NJ): Novartis Pharmaceuticals Corporation, 2015.

13. Metadate $\mathrm{CD}^{\circledR}$ (methylphenidate HCL): US prescribing information. Smyrna (GA): UCB Inc., 2015.

14. Ritalin $\mathrm{LA}^{\circledR}$ (methylphenidate hydrochloride extended release): US prescribing information, East Hanover (NJ): Novartis Pharmaceuticals Corporation, 2015.

15. Vyvanse ${ }^{\circledR}$ (lisdexamfetamine dimesylate): US prescribing information. Lexington (MA): Shire US Inc., 2017.

16. Tulloch SJ, Zhang Y, McLean A, Wolf KN. SLI381 (Adderall $\mathrm{XR}$ ), a two-component, extended-release formulation of mixed amphetamine salts: bioavailability of three test formulations and comparison of fasted, fed, and sprinkled administration. Pharmacotherapy. 2002;22(11):1405-15.
17. Ermer J, Corcoran M, Lasseter K, Martin PT. Relative bioavailabilities of lisdexamfetamine dimesylate and D-amphetamine in healthy adults in an open-label, randomized, crossover study after mixing lisdexamfetamine dimesylate with food or drink. Ther Drug Monit. 2016;38(6):769-76.

18. Pentikis HS, Simmons RD, Benedict MF, Hatch SJ. Methylphenidate bioavailability in adults when an extended-release multiparticulate formulation is administered sprinkled on food or as an intact capsule. J Am Acad Child Adolesc Psychiatry. 2002;41(4):443-9.

19. Krishnan S, Zhang Y. Relative bioavailability of lisdexamfetamine 70-mg capsules in fasted and fed healthy adult volunteers and in solution: a single-dose, crossover pharmacokinetic study. J Clin Pharmacol. 2008;48(3):293-302.

20. Stark JG, Engelking D, McMahen R, Sikes C. A randomized crossover study to assess the pharmacokinetics of a novel amphetamine extended-release orally disintegrating tablet in healthy adults. Postgrad Med. 2016;128(7):648-55.

21. Ermer JC, Shojaei A, Pennick M, Anderson CS, Silverberg A, Youcha SH. Bioavailability of triple-bead mixed amphetamine salts compared with a dose-augmentation strategy of mixed amphetamine salts extended release plus mixed amphetamine salts immediate release. Curr Med Res Opin. 2007;23(5):1067-75.

22. Adler LA, Goodman DW, Kollins SH, Weisler RH, Krishnan S, Zhang Y, et al. Double-blind, placebo-controlled study of the efficacy and safety of lisdexamfetamine dimesylate in adults with attention-deficit/hyperactivity disorder. J Clin Psychiatry. 2008;69(9):1364-73.

23. Weisler RH, Biederman J, Spencer TJ, Wilens TE, Faraone SV, Chrisman AK, et al. Mixed amphetamine salts extended-release in the treatment of adult ADHD: a randomized, controlled trial. CNS Spectr. 2006;11(8):625-39.

24. Stiefel G, Besag FM. Cardiovascular effects of methylphenidate, amphetamines and atomoxetine in the treatment of attention-deficit hyperactivity disorder. Drug Saf. 2010;33(10):821-42.

25. Westover AN, Halm EA. Do prescription stimulants increase the risk of adverse cardiovascular events? A systematic review. BMC Cardiovasc Disord. 2012;12:41.

26. Ermer J, Corcoran M, Lasseter K, Marbury T, Yan B, Martin PT. A single-dose, open-label study of the pharmacokinetics, safety, and tolerability of lisdexamfetamine dimesylate in individuals with normal and impaired renal function. Ther Drug Monit. 2016;38(4):546-55. 